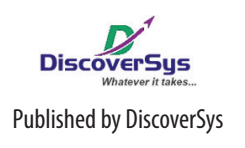

\title{
Kondisi penyakit-penyakit kronik: tantangan pelayanan kesehatan abad ke-21 dan masukan untuk implementasi Jaminan Kesehatan Nasional
} 2014

\author{
I Wayan Weta*
}

\begin{abstract}
Bagian IImu Kedokteran Komunitas dan Pencegahan, Fakultas Kedokteran Universitas Udayana
\end{abstract}

*Correspondence to: I Wayan Weta, Bagian IImu Kedokteran Komunitas dan Pencegahan, Fakultas

Kedokteran Universitas Udayana

\section{PENDAHULUAN}

Seiring dengan perubahan lingkungan dan perilaku masyarakat, tidak ada satu negarapun di dunia yang luput dari peningkatan kejadian penyakit kronik. Peningkatan dramatis morbiditas dan mortalitas akibat penyakit-penyakit kronik, baik penyakit tidak menular seperti kelompok penyakit degeneratif, metabolik, malnutrisi, gangguan mental maupun beberapa penyakit menular seperti tuberkulosis, HIV dan AIDS, menyebabkan peningkatan pembiayaan pelayanan kesehatan. Kondisi ini perlu mendapat perhatian dan penyikapan serius, oleh karena dalam penanggulangannya, penyakit kronik perlu manajemen pelayanan khusus dengan pembiayaan relatif besar. Penyakit degeneratif umumnya memerlukan perawatan secara berkesinambungan dalam jangka waktu lama (sampai seumur hidup) dengan pembiayaan yang cukup mahal. Untuk mengantisipasi masalah tersebut, sistem pelayanan kesehatan harus dikembangkan sesuai dengan pola kejadian penyakit. ${ }^{1}$

Saat ini sebagian besar pola pelayanan dari semua strata di Indonesia, baik tingkat primer, sekunder maupun tersier, masih berorientasi pada pendekatan pelayanan yang sebenarnya hanya efektif untuk penyakit akut (doctor centre). Pendekatan pelayanan doctor centre tidak efektif untuk penanggulangan penyakit-penyakit kronik. ${ }^{1,2}$ Pendekatan pelayanan penyakit kronik harusnya dibuat berbeda dengan pelayanan pada penyakit akut. Penyakit akut umumnya memerlukan pendekatan pelayanan crossectional. Pelayanan dengan pendekatan doctor centre pada penyakit kronik hanya akan meningkatkan unit cost pelayanan, sehingga hasil akhirnya tidak costeffective. Untuk menghasilkan pelayanan yang cost effective, haruslah dikembangkan pelayanan kesehatan terkelola dan terstruktur yang dikenal sebagai managed health care (managed care). Managed care berorientasi pada pelayanan terkendali, baik dari segi mutu pelayanan maupun pembiayaan.

Pola penanggulangan penyakit kronik seharusnya mengacu pada sisi kepentingan dan kapasitas pasien serta keluarganya (patient centre).
Pasien dan keluarganya harus menjadi subyek pelaku yang aktif dan partisipatif dalam program perawatan penyakit yang dideritanya. Karena perawatan penyakit kronik umumnya memerlukan perawatan dalam jangka waktu lama, terprogram, pelayanan bersinambungan, dengan tingkat partisipasi dan kepatuhan tinggi. Penanggulangan penyakit degeneratif secara keseluruhan di masyarakat hendaknya memakai pendekatan yang bersifat komprehensif dan terpadu.

Pendekatan secara komprehensif yang meliputi upaya promotif, preventif dilakukan pada komunitas, selain kuratif dan rehabilitatif pada penderita. Sedangkan pendekatan terpadu umumnya merupakan kerja sama dari berbagai komponen terkait untuk ikut berkontribusi dalam pengembangan sistem pelayanan kesehatan.

\section{PEMBAHASAN}

\section{Managed Care Pada Penyakit Kronik}

Rendahnya efektivitas penanganan penyakit kronik disebabkan oleh kelemahan pada setiap level sistem penanganan pelayanan kesehatan. Menurut WHO, sistem pelayanan kesehatan berproses pada tiga tingkatan yaitu level mikro, meso dan makro. Pada level mikro terjadi interaksi dokter dengan pasien dan keluarganya, sedangkan level meso merupakan proses pelaksanaan peran organisasi pelayanan kesehatan dan level makro merupakan peran pemegang kebijakan. Ketiga level tersebut berinteraksi satu sama lainnya secara dinamis. Bila level mikro, meso dan makro bekerja secara intensif, dan interaksi satu sama lain berjalan dengan baik, maka pelayanan kesehatan akan menjadi efisien dan efektif. Sebaliknya disfungsi pada masingmasing level akan menghasilkan pemborosan dan mengakibatkan ketidak-efektifan.

Beberapa kelemahan pada level mikro sering terjadi berupa: (1) kegagalan pemberdayaan pasien disebabkan oleh tidak efektifnya konseling, edukasi dan pemberian umpan balik dan (2) kegagalan dalam hal berinteraksi dalam proses pengambilan keputusan dan rencana perawatan. Masalah pada level meso dapat berupa: (1) kegagalan 
mengorganisasikan pelayanan penyakit-penyakit kronis, dimana penekanan pengobatannya umumnya hanya tertuju pada penyakitnya, bukan pada siapa yang sakit, sehingga upaya pemberdayaan pasien dan keluarganya melalui perubahan sikap dan perilaku sangat rendah; (2) rendahnya penguasaan keilmuan dan tidak jelasnya standar prosedur operasional (SPO) pelayanan, melahirkan pelayanan yang tidak berkualitas; (3) pelayanan yang tidak berbasis bukti (evidence-based practices); (4) kegagalan melakukan pencegahan, orientasi pelayanan kuratif; (5) sistem informasi tidak tepat guna; dan (6) kegagalan melakukan kontak dengan sumber daya masyarakat. Sedangkan kelemahan menonjol pada level makro adalah dalam hal: (1) kerangka kerja yang tidak jelas; (2) kebijakan dan rencana yang tidak sesuai (outmodel); (3) investasi pemerintah terbatas; (4) sistem pembiayaan terfragmentasi; dan (5) incentive pada provider rendah. ${ }^{1}$

Hasil akhirnya bisa kita lihat kondisi perawatan penyakit-penyakit kronis saat ini seperti hipertensi, diabetes melitus, tuberkulosis dan sebagainya, sangat tergantung pada dokter dan obat-obatan. Peran pasien dan keluarga hanya menonjol dari segi pembiayaannya saja, sedangkan peran perubahan sikap dan perilaku untuk memberdayakan mereka sebagai subjek pelaku utama dalam penanggulangan penyakitnya masih sangat kurang. Kalau kondisi ini terus dibiarkan akan berdampak pada rendahnya tingkat kepatuhan pasien dalam program perawatan dan pengobatan penyakitnya, sehingga dengan sendirinya mempengaruhi tingkat kesembuhannya.

Menyadari kelemahan sistem pelayanan kesehatan tersebut, sudah selayaknya ada perubahan paradigma pelayanan. Pendekatan pelayanan penyakit-penyakit kronis harus bertumpu pada peran pasien dan keluarganya (patient centre), melalui perubahan perilaku yang meliputi gaya hidup, pola makan, aktifitas fisik dan kepatuhan mengikuti aturan perawatan. Pada akhirnya dapat meningkatkan efektifitas pengobatan. Harus terjadi perubahan orientasi dari pendekatan doctor centre ke arah patient centre. ${ }^{3}$ Penanggulangan penyakit kronis berbasis perubahan perilaku pasien, memerlukan pendekatan komunikasi yang intensif antara dokter dengan pasien dan keluarganya melalui manajemen pelayanan partisipatif. Komunikasi yang intensif, pelayanan yang komprehensif, kontinus, koordinatif dan kolaboratif yang merupakan ciri dari pendekatan pelayanan kedokteran keluarga, telah dianjurkan oleh WHO dan Asosiasi Kedokteran Keluarga Dunia (WONCA) untuk dilaksanakan di negara-negara anggotanya. ${ }^{4}$ Untuk mewujudkan efektivitas pelayanan harus dibangun sistem kesehatan nasional yang merangkul dan memberi peran pada tiga komponen utama yang terdiri dari komunitas (mikro), organisasi pelayanan kesehatan (meso) dan pemegang kebijakan (makro). Keharmonisan antar komponen akan menciptakan hubungan sinergis satu sama lain. Komunitas berperan dalam: peningkatan kepedulian dan mengurangi stigma, mendorong peningkatan outcome melalui kepemimpinan dan pemberian dukungan, memobilisasi dan mengkoordinasi sumber daya dan bila perlu menciptakan pelayanan pelengkap (komplementer). Organisasi pelayanan kesehatan beperan sebagai motivator dalam hal: peningkatan kontinuitas dan koordinasi, mendorong mutu pelayanan melalui kepemimpinan, pemberian apresiasi dan insentif, pengorganisasian dan pemerataan tim pelayanan kesehatan, penggunaan sistem informasi dan pemberdayaan masyarakat dalam hal pencegahan dan penanganan mandiri. Sedangkan pemegang kebijakan berperan dalam hal: penguatan kemitraan, mendukung kerangka kerja legislasi, kebijakan terpadu, mewujudkan kepemimpinan dan advokasi, meningkatkan konsistensi pembiayaan, membangun dan mengalokasikan sumber daya manusia. ${ }^{1}$ Dengan demikian diharapkan outcome pelayanan pada penyakit-penyakit kronis akan menjadi lebih baik.

Perubahan paradigma pendekatan pelayanan kesehatan di atas harus diikuti oleh suatu perubahan sistem pelayanan kesehatan itu sendiri. Pendekatan penanggulangan penyakitpun harus dimulai pada saat sehat (paradigma sehat), melalui upaya-upaya yang bersifat promotif dan preventif, disamping upaya yang bersifat kuratif dan rehabilitatif (paradigma sakit). Kondisi pelayanan kesehatan di negara-nagara maju umumnya sudah menerapkan sistem pelayanan kesehatan yang terstruktur, sedangkan untuk negaranegara berkembang mulai menciptakan sistem pelayanan tersebut. Di Indonesia, perubahan paradigma ini dimulai dengan diwacanakannya Indonesia Sehat tahun 2010 oleh pemerintah di awal gerakan reformasi. Kemudian dilanjutkan dengan telah ditetapkannya Sistem Kesehatan Nasional melalui SK Menteri Kesehatan RI, ${ }^{5}$ dan diundangkannya Sistem Jaminan Sosial Nasional (SJSN) (Undang-Undang Nomor 40 tahun 2004), dimana jaminan kesehatan ada di dalamnya. ${ }^{6}$ Undang-undang SJSN diimplementasikan dalam bentuk Jaminan Kesehatan Nasional (JKN) pada seluruh masyarakat Indonesia mulai tahun 2014. ${ }^{7}$ Kemudian di level global juga dirumuskan 
Millenium Development Goals (MDGs) yang menetapkan beberapa indikator yang harus dicapai khususnya untuk negara-negara berkembang pada akhir tahun 2015. Indikator kesehatan merupakan bagian utama dari semua indikator MDGs, dimana penyakit kronik juga masuk didalamnya.

Pelayanan kesehatan berbasis asuransi kesehatan sosial sebagai implementasi undang-undang SJSN 2004, diterapkan secara universal mulai tahun 2014, dalam bentuk Jaminan Kesehatan Nasional (JKN). JKN memberikan pelayanan secara berjenjang dengan sistem rujukan, mulai dari pelayanan primer atau pemberi pelayanan strata 1 (PPK1), sekunder (PPK2) dan tersier (PPK3). JKN menerapkan sistem pembiayaan prabayar, melalui sistem kapitasi pada PPK1, dan INA CBGs (DRGs versi Indonesia) pada pelayanan PPK2 dan PPK3. Pembayaran kapitasi pada PPK1 didasarkan atas jumlah anggota (tetap) dengan besaran tetap setiap bulan. Sedangkan pada PPK2 dan PPK3, melalui INA CBGs pembayaran didasarkan atas kelompok diagnosis penyakit. Satu kelompok diagnosis penyakit ditetapkan satu tarif. Pembiayaan prabayar seperti ini menjamin kepastian biaya kesehatan pada besaran tertentu. Melalui pembiayaan prabayar dengan besaran tertentu tersebut, semua provider kesehatan pada semua strata pelayanan, dipaksa melakukan efisiensi dalam melaksanakan pelayanan tanpa mengurangi kualitasnya. ${ }^{8}$ Sistem pelayanan kesehatan seperti ini pada akhirnya akan melahirkan pelayanan yang terkendali biaya dan terkendali mutu, yang dikenal sebagai pelayanan yang berbasis managed care. Pada PPK1, provider selayaknya mempunyai kompetensi tertentu (kedokteran keluarga), dengan pendekatan pelayanan yang komprehensif, yang penekanannya lebih pada upaya yang bersifat promotif dan preventif. ${ }^{9}$ Demikian juga di level pelayanan sekunder dan tersier harus diisi oleh provider yang kompeten di bidangnya sehingga menghasilkan output pelayanan yang cost-effective. Dengan penerapan managed care, biaya pelayanan, khususnya penyakit-penyakit kronik yang notabene memerlukan perawatan jangka panjang dan mahal bisa ditekan. Pelaksanaan JKN yang berbasis managed care ini akan mampu menyediakan pelayanan kesehatan yang layak, bermutu dan terjangkau bagi seluruh masyarakat Indonesia. Untuk mewujudkan hal tersebut, semua pengampu kepentingan (stakeholders) terkait harus bekerja keras, bahu membahu satu sama lain sesuai dengan kompetensinya guna menyukseskan program JKN yang telah lama diimpikan masyarakat.

Dari segi sumber daya manusia (SDM) kesehatan, telah disahkan Undang-Undang tentang Praktek Kedokteran (UUPK) (Nomor 29 Tahun 2004). ${ }^{10}$ Dilihat dari sisi provider, secara implisit dalam UUPK tersebut sebenarnya termaktub agar para dokter meningkatkan kompetensi dan profesionalismenya dalam pemberian pelayanan kesehatan kepada masyarakat. Seorang dokter harus melaksanakan tugasnya secara profesional, terukur (accountable) dan bertanggung jawab. Sebab kalau tidak, ada konsekuensi sanksi baik etika maupun hukum, yang mengintai para dokter dalam melaksanakan profesinya, bila seorang dokter melakukan pelanggaran dan atau kesalahan. ${ }^{11}$

\section{Reformasi Pendidikan SDM Kesehatan}

Dalam rangka penyiapan SDM kesehatan untuk mengisi sistem tersebut, secara global di berbagai belahan dunia juga mulai dilakukan reformasi pendidikan dokter. Dalam Undergraduate Medical Education for the $21^{\text {st }}$ Century (UME21) dirumuskan area konten dari kurikulum pendidikan dokter meliputi: (1) sistem pembiayaan, ekonomi, organisasi dan pelayanan kesehatan; (2) pendekatan evidence based, epidemiologi, dengan penekanan pada perspektif populasi; (3) etika; (4) pengembangan hubungan yang efektif pasien-provider dan keterampilan komunikasi; (5) kepemimpinan; (6) pengukuran dan peningkatan kualitas, meliputi cost-effectiveness dan kepuasan pasien; (7) pelayanan berbasis sistem; (8) medical informatics; dan (9) pemeliharaan kesehatan (wellness) dan pencegahan penyakit (prevention). ${ }^{12}$

Di Indonesia juga telah tersusun kurikulum nasional berbasis kompetensi (KBK) yang juga dikenal sebagai KIPDI-III. Kurikulum ini wajib dilaksanakan oleh seluruh institusi pendidikan dokter di seluruh wilayah Indonesia. ${ }^{13}$ Dalam kurikulum pendidikan dokter secara umum, yang dijiwai oleh butir-butir UME-21 di atas, dirumuskan kompetensi lulusan dokter pelayanan primer melalui pendekatan kedokteran keluarga. ${ }^{11,12}$ Dengan demikian the five stars doctor yang direkomendasikan oleh WHO dan WONCA diharapkan dapat diimplementasikan dengan baik dalam praktek kedokteran.

Para dokter yang telah ada dan lama berpraktikpun juga sudah mulai diupayakan pengenalan konsep dan implementasi pelayanan kedokteran keluarga melalui modul-modul pelatihan kedokteran keluarga. Dokter yang telah lama menjalankan praktik mau tidak mau harus mengikutinya, bila tidak ingin tergilas roda reformasi sistem pelayanan kesehatan tersebut. Dengan demikian diharapkan akan memberikan solusi untuk menjawab tantangan kondisi penyakitpenyakit kronis ke depan. Dokter di masa depan tidak semata-mata menjadi penyembuh, akan tetapi juga sebagai penyehat bagi kliennya melalui suatu hubungan partisipatif yang harmonis dan humanis. ${ }^{3,9}$ 


\section{REKOMENDASI}

Diterapkannya JKN mulai tahun 2014 merupakan momentum yang sangat penting dalam penerapan managed care guna menghasilkan pelayanan yang cost-effective. Untuk mencapai tujuan tersebut diperlukan pembenahan dan penguatan kelembagaan pada masing-masing level komponen pelayanan kesehatan, mulai dari level makro, meso dan mikro.

\section{Level Makro}

Pada level makro, pemerintah telah menetapkan kebijakan pelaksanaan JKN mulai tahun 2014, yang dituangkan dalam Peraturan Presiden Republik Indonesia, Nomor 12 Tahun 2013. Seyogyanya ditindaklanjuti pemerintah, melalui berbagai peraturan dan pedoman pelaksanaan, melakukan advokasi, sosialisasi, dan fasilitasi, sehingga JKN benar-benar siap diluncurkan pada awal tahun 2014.

Penguatan Kelembagaan BPJS Kesehatan, transformasi PT Askes menjadi BPJS Kesehatan dirancang agar terjadi perubahan prinsip yang semula berorientasi profit ke arah sosial (nirlaba). berlawanan dari yang semula berorientasi profit ke arah sosial (nirlaba). Visi dan misi utama dari BPJS Kesehatan haruslah semata-mata social oriented untuk meningkatkan derajat kesehatan masyarakat melalui penyediaan pelayanan kesehatan yang layak, bermutu dan terjangkau.

Penguatan kelembagaan pendidikan SDM kesehatan, kebijakan pendidikan tenaga kesehatan, hendaknya dirancang untuk menghasilkan SDM kesehatan yang berkualitas untuk mengemban tugas pada sistem pelayanan JKN yang dilaksanakan secara berjenjang dengan penerapan managed care.

Besaran kapitasi dan tarif INA CBGs hendaknya layak untuk memenuhi kebutuhan hidup provider, termasuk untuk memenuhi kebutuhan biaya pengembangan diri atau profesionalisme. Hal ini sangat penting, karena setiap penduduk wajib sebagai peserta JKN (universal coverage), PPK tidak lagi mendapat kesempatan pembayaran langsung dari pasien, secara fee for service atau out of the pocket. BPJS Kesehatan juga harus mengakomodir upaya-upaya yang bersifat promosi kesehatan dan pencegahan penyakit, serta sistem penapisan dan penanganan penyakit kronik stadium dini. Dewan Jaminan Sosial Nasional (DJSN) harus bekerja keras untuk mewujudkan situasi dan kondisi tersebut di atas.

\section{Level Meso}

Harus ada pembenahan dan penguatan pemberi pelayanan kesehatan mulai dari PPK1, PPK2 dan
PPK3. Penguatan PPK1 (puskesmas dan dokter umum/dokter keluarga), SDM kesehatan pada PPK1 harus kompeten dan terampil dalam melakukan upaya promotif dan preventif, disamping upaya kuratif dan relabilitatif pada level pelayanan primer. Penguatan rumah sakit/klinik spesialis, sebagai PPK2 dan PPK3. Rumah sakit harus diisi oleh dokter spesialis yang terampil dalam bidangnya. Asosiasi profesi seperti IDI, perkumpulan dokter umum, organisasi dokter spesialis dan sebagainya harus proaktif meningkatkan kompetensi dan profesionalisme anggotanya, melalui kegiatan continuing medical education dan atau continuing professional development. Disamping itu asosiasi profesi harus membenahi sistem pemberian rekomendasi kelayakan kompetensi yang dimiliki anggotanya sebagai provider kesehatan, yang selama ini terkesan hanya formalitas belaka.

Harus ada sistem upaya deteksi dini (screening) yang diakomodir oleh BPJS, misalnya general check up rutin agar penanggulangan penyakit (kronik) dapat dilakukan sedini mungkin. Setiap institusi pelayanan kesehatan harus memiliki manajemen pelayanan yang terstruktur, harus memiliki SPO tertulis untuk setiap tindakan medis yang dilaksanakan. Setiap tindakan medis yang dilaksanakan harus dapat dipertanggungjawabkan.

\section{Level Mikro}

Harus dilakukan sosialisasi yang sistematis dan intensif pada seluruh masyarakat, agar tujuan yang mulia ini dipahami dan didukung oleh seluruh lapisan masyarakat. Stigma yang mungkin ada akibat pengalaman pelayanan asuransi kesehatan sebelumnya, seperti pelayanan yang birokratis, pelayanan yang dijamin hanya yang berbiaya murah, pelayanan yang mahal walau esensial sering tidak dilayani, sehingga mereka merasa kurang puas pada pelayanan asuransi kesehatan. Persepsi ini harus diantisipasi, diluruskan dan disadarkan, bahwa oleh karena relatif mahalnya biaya pelayanan kesehatan inilah diperlukan asuransi/jaminan kesehatan dimana ada prinsip gotong royong (sharing risk) didalamnya. Ada subsidi silang antar peserta JKN yang berbasis asuransi sosial, yang sehat membantu yang sakit, yang kaya membantu yang miskin, yang muda membantu yang tua.

Pada prinsipnya melalui JKN ini kita bergotong royong dalam membiayai pelayanan kesehatan, mereka yang berisiko rendah membantu saudaranya yang berisiko tinggi. Untuk mencapai hal tersebut perlu komunikasi yang sistematis dan intensif antara pemegang kebijakan dengan masyarakat, antara organisasi PPK dengan masyarakat dan antara kelompok masyarakat itu sendiri. 


\section{DAFTAR PUSTAKA}

1. WHO. Innovative care for chronic conditions- building blocks for action; 2002.

2. Brodsky J, Habib J, Hirshfed M. Long-term care in developing countries. Ten case-studies. WHO-Geneva and JDC-Brookdale Institute; 2003.

3. Goh LG, Azwar A, Wonodirekso S. A primer on family medicine practice. Singapore International Foundation; 2004.

4. Boelen C, Haq C, Hunt V, Rivo M, Shahady E. Improving Health System: The Contriburtion of Family Medicine. A Guide Book. Wonca. Singapore; 2002.

5. Departemen Kesehatan RI. Sistem Kesehatan Nasional. Jakarta; 2004.

6. Undang-undang Republik Indonesia Nomor 40 tahun 2004 tentang Sistem Jaminan Sosial Nasional. Jakarta; 2004.

7. Peraturan Presiden Republik Indonesia, Nomor 12 Tahun 2013 tentang Jaminan Kesehatan. Jakarta; 2013.

8. Departemen Kesehatan Republik Indonesia. Peta Jalan Menuju Jaminan Kesehatan Nasional 2014-2019; 2013.
9. Weta, IW. Pelayanan kesehatan primer dengan pendekatan kedokteran keluarga, tantangan dan harapan kedepan. MKU 2005; 36 (129): 149-154.

10. Undang-Undang Republik Indonesia Nomor 29 Tahun 2004 tentang Praktek Kedokteran. Jakarta; 2003.

11. Weta, IW. Menyongsong diberlakukannya undang-undang praktek kedokteran (editorial). MKU 2006; 37 (131):1

12. Bazell C, Davis H, Glass J, Rodak J Jr, Bastacky SM. The Undergraduate Medical Education for the $21^{\text {st }}$ Century (UME-21) Project: The Federal Government Perspective. Fam Med 2004; 36 (January suppl):S15-S19.

13. Department of National Education. National CompetencyBased Curriculum for the Primary Care Physician in Indonesia. Jakarta, 2004.

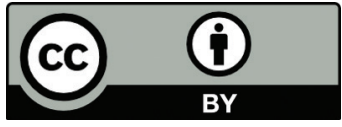

This work is licensed under a Creative Commons Attribution 